\title{
Impact of Leadership Efficacy on Teacher Teaching Performance in Elementary Schools
}

\author{
Apriant Cahyo Supriadi ${ }^{1,2^{*}}$, Asep Suryana ${ }^{1}$ \\ ${ }^{1}$ Educational Administration Department, ${ }^{2}$ Headmaster Elementary School 2 Cibinong \\ ${ }^{1}$ Universitas Pendidikan Indonesia \\ ${ }^{1}$ Bandung, ${ }^{2}$ Purwakarta, Indonesia \\ *apriantcahyo1970@gmail.com
}

\begin{abstract}
The contribution of leadership efficacy has been extensively researched, and the results have contributed positively to teacher performance. This research aims to complete the previous research by reviewing the specific scope that is in elementary school. This research was conducted using descriptive quantitative methods against 244 elementary school teachers in Pasawahan District, Purwakarta Regency. Data is obtained through the spread of polls and processed with regression analysis. The results showed that leadership efficacy had a positive effect on teaching performance. Teaching performance can grow when the principal has high leadership efficacy.
\end{abstract}

Keywords-leadership, leadership efficacy, teaching performance

\section{INTRODUCTION}

Teacher performance teaching is influenced by many factors, not only from the internal elements of the teacher. Other factors such as environment, coworkers, school policies, and school principals also cannot be separated from the factors that have a dominant influence on teacher performance in teaching. Teachers as educators have heavy duties and responsibilities. The teacher must realize that he has to do his job seriously, responsibly, sincerely and not carelessly, so that students can easily accept whatever the teacher says. If this is achieved, the teacher will have a high level of performance.

A number of studies have obtained results where the leader factor has a close relationship with subordinates through the leadership efficacy channel [1]. Leaders and followers interact reciprocally through the belief process. Leadership efficacy can influence the dynamics of leader-follower interactions in ways that leaders may not want. In particular, the efficacy of followers at critical moments can strengthen the leader to move forward, which in turn can increase the confidence of subordinates, resulting in patterns with each collectively.

In educational organizations such as schools, interactions occur between principals and teachers. Instructional interactions can occur when the principal wants a change in teacher performance in the teaching process. This kind of interaction can work effectively when the principal has high confidence in leading, given that there is a tendency for teachers to refuse the instructions given so that what the school goals cannot be realized. School as a place to educate students, relies on the figure of a teacher who carries out teaching tasks. Therefore, teaching performance has a dominant role in educating children to succeed in learning. Teaching performance is the activity and work behavior of the teacher which is based on the knowledge and ability to make lesson plans, carry out learning and carry out learning evaluations.

Self-efficacy is a concept developed by Albert Bandura in the early 1960s, which emphasizes how much individuals believe in their abilities to be successful in their work. Leadership self-efficacy is an identification of how a leader's perceptions affect those who follow him. From a number of studies in the last two decades, it is suggested that subordinates will change their behavior if the leader shows confidence in his own leadership skills.

Psychological conditions such as self-efficacy can directly promote effective leader engagement, increase flexibility and adaptability across a variety of challenges that characterize complex organizational contexts [2]. This condition occurs because the high efficiency of the leader can provide internal guidance and encouragement to create the institutions needed to successfully pursue challenging tasks and opportunities ahead [3-5].

Leadership efficacy is a specific belief with a level of confidence in the knowledge, skills, and abilities associated with leading others. This concept separates beliefs from the knowledge, skills and abilities a person holds in relation to other social roles.

In 2008, researchers sought to create a taxonomy of the factors that determine leadership efficacy. The aim of this research is to find measurable leadership factors, thus making the impact analysis as early as possible. At the end of the study, 88 attributes were formulated in five categories. A further meta-analysis found that when several attributes were combined, the correlation with leadership effectiveness increased. Unfortunately, there is no consistent set of attributes that lead to the effectiveness of this taxonomy. 
Confidence in a leader is very necessary when facing uncertainty in organizations like today. Today's leaders face unprecedented challenges as organizations struggle to adapt to an ever-increasing rate of change. The challenges of change are not only the knowledge, skills and abilities of leaders. But the self-conceptualization of leadership abilities, and the fulfillment of the increasing psychological resources of their roles $[6,7]$.

Knowing whether the leader has strong efficacy, a number of things can be considered as assessment parameters, such as: 1) Attributes of leadership; how well the leader creates a vision for the future, 2) Management attributes; how well the leader supervises the daily operations of the team, 3) Problem solving attributes; how well the leader solves problems or empowers the team to solve problems, 4) Social / communication attributes; how well the leader communicates the vision, goals and responsibilities of the team, 5) General work attributes; how you approach work from an emotional perspective, with factors such as humility or persistence.

In a broader context, where the leader has the responsibility to improve the performance of his subordinates. It is necessary for leaders through self-efficacy first to: 1) investigate the hierarchical structure of the level of leadership efficacy, which we consist of self-efficacy, the meaning of efficacy, and certain domains of self-efficacy, as well as interactions between various forms of efficacy in facilitating effective performance; 2) increase a deeper understanding of how self-efficacy develops and operates in the self-system of leaders and affects cognition and influences behavior; 3) establish a multi-level approach to understanding the emergence of efficacy in organizations, including subordinates, team / collective and organizational levels.

Previous research as mentioned in the previous paragraph, leadership efficacy's studies are more on non-educational organizations. Research that examines leadership efficacy in schools is still very limited, especially at the elementary school level. Therefore, researchers intend to complete the previous study by focusing on the influence of leadership efficacy on teaching performance in elementary schools.

\section{METHODS}

The dimensions studied in the researcher's leadership efficacy take from the constructs proposed by Hannah et al (2008), including: leader efficacy for through, leader efficacy for self-motivation, leader efficacy for means, and leader efficacy for action. Meanwhile, the measurement for teaching performance is preparation, presentation, execution/ methods, personal characteristics, and teacher student interaction.

The purpose of this study was to obtain the magnitude of the influence of leadership efficacy on teaching performance in public elementary schools in Pasawahan District, Purwakarta Regency. In this study, the researcher used a descriptive quantitative approach to explain the current phenomena with regard to the established research focus. The data were collected using purposive sampling technique on 244 elementary school teachers. Through the distribution of questionnaires, researchers conducted data mining on respondents and obtained data collected by 69 respondents. Determination of purposive sampling is in order to facilitate the conclusion of research results. The criteria set in this determination are: 1) the respondent has the status of a civil servant, 2) has a service period of more than 5 years, and 3) is certified. The data obtained then the researchers processed with simple regression analysis techniques to obtain the regression coefficient and determination.

\section{RESULTS AND DISCUSSION}

The regression test was conducted to answer the research questions asked. The previous discussion by the researcher had explained that this study was intended to obtain the magnitude of the level of influence of leadership efficacy on teaching performance in elementary school teachers, whether the effect was positive or vice versa. In addition, the researcher also wants to get a definite picture of the strength of this influence so that it becomes a future prediction for better leadership efficacy practices. Tests were carried out using the XLSTAT, and the results are obtained as shown in the table 1 below.

TABLE I. REGRESSION TEST

\begin{tabular}{|l|l|l|l|l|}
\hline \multicolumn{1}{|c|}{ Source } & Value & $\begin{array}{c}\text { Standard } \\
\text { error }\end{array}$ & \multicolumn{1}{c|}{$\mathbf{t}$} & \multicolumn{1}{c|}{ Pr $>|\mathbf{t}|$} \\
\hline Intercept & 3.706 & 1.404 & 2.639 & $\mathbf{0 . 0 1 0}$ \\
\hline Leadership Efficacy & 1.272 & 0.102 & 12.478 & $<\mathbf{0 . 0 0 0 1}$ \\
\hline
\end{tabular}

The test results as shown in the intercept column obtained regression coefficient values of 3.706 and 1.272 on leadership efficacy. Both values are positive, meaning that they have a unidirectional relationship in effect. From the coefficient, it means that when there is an increase of 1.272 in leadership efficacy, then this will have an impact on the increase in teaching performance by 3.706 linearly. Furthermore, the $t$ value also shows the amount above the requirement test limit, which is $12.478(0.0001)$ so it can be said that leadership efficacy has a significant effect on teaching performance in primary school teachers. To find out how strong this leadership efficacy is to determine teaching performance, the data processing graph can be shown as in figure 1 follows. 


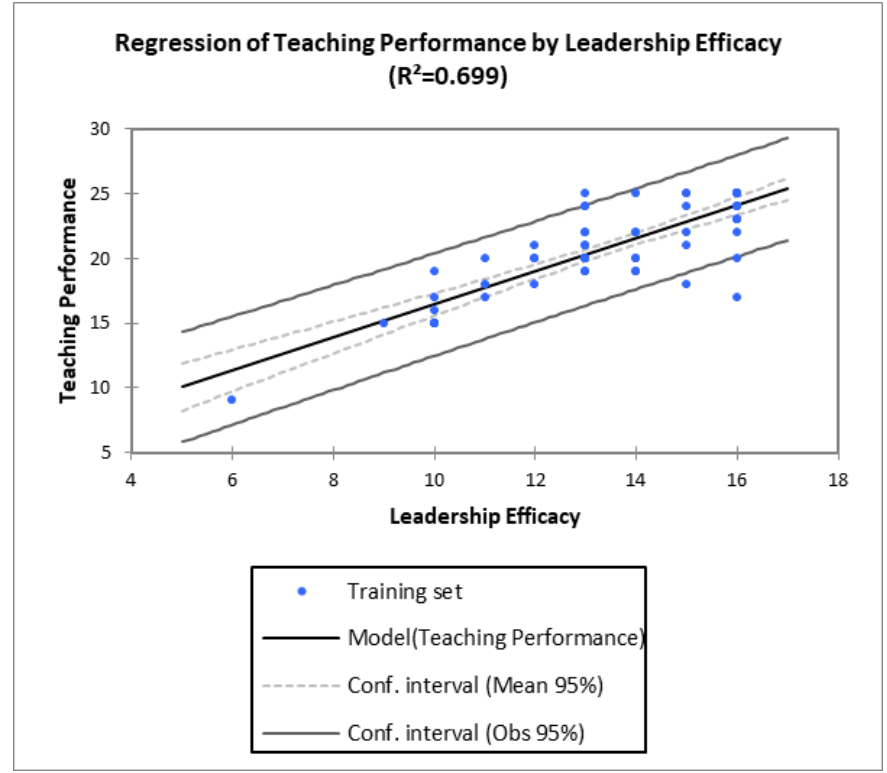

Fig. 1. Regression of teaching performance.

The figure 1 above shows the linear influence of leadership efficacy on teaching performance in elementary school teachers. As for strength, with an R square of 0.699 or $69.9 \%$, it can be interpreted that leadership efficacy strongly determines the improvement of teaching performance. Another meaning of this result is that leadership efficacy can be used as the main variable in improving teacher teaching performance.

The role of teachers in schools has evolved and relevant teaching and learning processes have to be defined, so that their improvement has been prioritized in various ways, one of which is a leadership role. The teaching implementation is implemented as a pedagogical practice that can be observed and manifest itself. When the teacher expresses his competence and is related to the expected learning achievement, namely the intentionality of education and the implementation of the assigned task. In the population, teaching performance depends on different factors related to the quality and initial training of teachers to achieve a level of excellence in education [8]

The results of the above research indicate that leadership efficacy has an impact on increasing teaching performance in elementary school teachers. Previous research has shown that leaders can influence follower self-concept through role modeling [9].

Parallel to the information processing approach, followers tend to develop prototypical leadership quality schemes based on leader attractiveness. This shows that leader's behavior can be prototypical in the form of ideal behavior that organizational members to submit and obey, and follow the directions given, including in the implementation of teaching tasks. Thus, higher levels of leader's self-efficacy can be expected to contribute to positive leader-follower relationships and performance over time [10].
The teaching given by the teacher must be done well, and be based on pedagogical theory, provide relevant content, become a driver of change in the evaluation system integrated into public policy, and propose strategies or models to solve various problems. In addition, teachers must also have certain professional qualities to deliver quality education, and have adequate professional competence. Professional competence is the ability teachers have and are manifested in the mastery of knowledge, skills, and the ability to carry out certain activities related to teaching. The formulation of competence is not the result of objective decisions, but is dynamic in nature and the result of two theoretical and ideological choices that provide great scope for interpretation. Therefore, with the advancement of science, technology and information media, it is only natural that there will be changes in competencies and strengthening of other skills and abilities needed.

The increase in teaching performance occurs because of the influence of the behavior of the leader, so that teachers are motivated to follow the instructions and directions given, either consciously or not. This process is passed from the cognition mechanism in the form of awareness of actions from the teacher, that what he does is beneficial for himself, others, and the organization. In this condition, the leader is a role model that is imitated and followed. In addition, persuasion and emotional arousal are important sources of self-efficacy development that encourage teachers to achieve their best in teaching. Leaders have the effect of emotional contagion through positive emotional communication channels to followers [11].

Principals with high efficacy can be effective problem solvers who can determine or become better communicators, become coaches, guides for teachers to teach quality. However, if leaders do not have adequate efficacy, effective leadership will not materialize so it will be difficult to lead teachers to teach well. Leaders with high efficacy can increase personal achievement in many ways. High efficacy people are able to approach difficult tasks and make them a challenge to master rather than a threat to be avoided.

The transformation of the school into a quality organization depends heavily on the extent to which the principal has high efficacy in mobilizes the people and resources they have. Confidence in the success of change must be demonstrated and transmitted to the school community [12]. The leader will set himself up by challenging goals and maintaining a strong commitment to subordinates.

\section{CONCLUSION}

The conclusion of this study is that leadership efficacy has a significant effect on teaching performance. Principal efficacy in managing school resources can contribute to increasing the ability of teachers to teach. Teachers will feel motivated when led by a principal who has a strong belief in the successes of the vision, mission and goals that have been set. As a recommendation from this study, namely in increasing leadership efficacy, principals can learn from the success of 
others, or through personal experience, as well as strengthen managerial competence and apply instructional leadership styles.

\section{REFERENCES}

[1] O. Doucet, G. Simard, and M. Tremblay, "Leadership and commitment: The mediating role of trust and support," Relations Ind., 2008.

[2] E. Adriasola and T. Hernandez, "Leader Identity Self-concordance: Is it what they do or how they signify what they do?," 2018.

[3] C. S. Carver and M. F. Scheier, Attention and Self-Regulation: A Control-Theory Approach to Human Behavior. 1981.

[4] R. Cropanzano and M. S. Mitchell, "Social exchange theory: An Interdisciplinary review," Journal of Management. 2005.
[5] W. Mischel and Y. Shoda, "A Cognitive-Affective System Theory of Personality: Reconceptualizing Situations, Dispositions, Dynamics, and Invariance in Personality Structure," Psychol. Rev., 1995.

[6] A. D. Stajkovic and F. Luthans, "Self-Efficacy and Work-Related Performance: A Meta-Analysis," Psychol. Bull., 1998.

[7] A. D. Stajkovic and F. Luthans, "Self-efficacy and work-related performance: A meta-analysis.," Psychol. Bull., 1998.

[8] J. Biggs, "Enhancing teaching through constructive alignment," High. Educ., 1996.

[9] B. J. Avolio and W. L. Gardner, "Authentic leadership development: Getting to the root of positive forms of leadership," Leadersh. Q., 2005.

[10] S. E. Murphy and E. A. Ensher, "A qualitative analysis of charismatic leadership in creative teams: The case of television directors," Leadersh. Q., 2008.

[11] L. J. Naidoo and R. G. Lord, "Speech imagery and perceptions of charisma: The mediating role of positive affect," Leadersh. Q., 2008

[12] S. Fitzgerald and N. S. Schutte, "Increasing transformational leadership through enhancing self-efficacy,” J. Manag. Dev., 2010. 